\title{
Risk factors for erectile dysfunction in end- stage renal disease patients with short- or long-term hemodialysis therapy
}

\author{
Hayato Nishida ${ }^{1 *}$, Atsushi Yamagishi', Toshihiko Sakurai ${ }^{1}$, Tomohiro Shibasaki ${ }^{1}$, Hisashi Kawazoe', \\ Osamu Ichiyanagi ${ }^{1}$, Tomoyuki Kato ${ }^{1}$, Akira Nagaoka' ${ }^{1}$, Yoshihiko Tomita ${ }^{2}$ and Norihiko Tsuchiya ${ }^{1}$
}

\begin{abstract}
Background: The influence of prolongation of hemodialysis (HD) period for erectile dysfunction (ED) has not been well evaluated. We evaluated the effects of various factors including hemodialysis duration for ED in hemodialysis patients.

Methods: One hundred seventy-eight HD patients including 50 patients who received HD more than 10 years were enrolled in this study. The questionnaire of the International Index of Erectile Function (IIEF)-5 in Japanese language was used for evaluation of ED status in this cohort. Various clinical factors of these patients were collected from review of medical records, and the relationship between these factors and ED status was also evaluated.

Results: The prevalence of diabetes $(p<0.001)$, obesity $(p=0.011)$, and hyperuricemia $(p=0.010)$ were significantly higher in patients with less than 10 years of HD (group 1) than those in patients with more than 10 years of HD periods (group 2). The mean score of IIEF-5 in group 2 was almost similar with that in group $1(p=0.452)$. Moderate to severe ED was also equivalent to that in group $1(p=0.988)$. More than 60 years old $(p<0.001)$ and absence of hyperuricemia $(p=0.002)$ appeared to be significant risk factors for moderate to severe ED in multivariate analysis.
\end{abstract}

Conclusions: Long periods of chronic hemodialysis therapy did not affect ED status, and absence of hyperuricemia was the risk factor for moderate to severe ED in HD patients.

Keywords: Erectile dysfunction, Hemodialysis, Renal failure, Hyperuricemia, IIEF-5

\section{Background}

Uremic condition is associated to various physical disorders which impair patient's quality of life. Erectile dysfunction (ED) is one of the common complications in male hemodialysis (HD) patients. Its prevalence is estimated to be approximately 20 to $80 \%$ in HD patients [1-6]. Various factors such as vascular dysfunction, neurogenic disturbance, adverse effect of medications, depression, hormonal abnormalities, anemia, secondary hyperparathyroidism, and zinc deficiency are related to ED in HD patients [3, 5-8]. Some of those risk factors for ED gradually progress with the extension of dialysis

\footnotetext{
* Correspondence: hnishida331@yahoo.co.jp

'Department of Urology, Yamagata University Faculty of Medicine, 2-2-2

lida-nishi, Yamagata 990-9585, Japan

Full list of author information is available at the end of the article
}

periods. However, whether long duration of HD is a significant risk factor of ED in HD patients is still controversial, because of the relatively short period of dialysis in those study cohorts and division of results. Moreover, the difference of clinical risk factor for ED between patients with short-term HD therapy and those with long-term therapy still remains uncertain. Hence, we evaluated the effects of various factors including HD duration for ED in HD patients.

\section{Methods \\ From January to July 2011, male patients who were older than 20 years old and received chronic HD therapy at 13 facilities in Yamagata prefecture were recruited to the study. The study protocol was approved by the ethical committee of the Yamagata University Faculty of Medicine.}


The patients who received providing written informed consent and voluntarily completed the questionnaire of the International Index of Erectile Function (IIEF)-5 in Japanese language that consisted of 5 questions eliciting were enrolled in the study. An IIEF-5 score between 1 to 7 denotes a serious form of ED, 8 to 11 denotes moderate, 12 to 16 denotes moderate to mild, 17 to 21 denotes mild, and 22 to 25 denotes no ED. The information about past history of smoking, alcohol consumption, presence of sexual partner, and past history of treatment for ED were also obtained by the questionnaire.

Terms of patient's background including age, duration of HD therapy, primary disease, presence of comorbidities, and current medications were collected from review of medical records. Attending physician in each facility evaluated the presence of each comorbidity based on patient's clinical status, laboratory data, and medication profile. Patients were divided into two groups: patients with less than 10 years of HD periods were in group 1, and those with more than 10 years were in group 2 .

Various parameters including patient's backgrounds and clinical features were compared between two groups. In order to evaluate differences between groups, Chi-square, Student's $t$ test, Mann-Whitney $U$ test, and Fisher's exact test were used as appropriate. Multivariate association between these factors and ED were measured with odds ratio (OR). Multivariable logistic regression analysis was used to examine the associations between predictor variables and ED. Significance of the individual regression estimates was tested by Wald statistics. The significance level was set at 0.05 for all tests. All statistical analyses were performed with EZR (Saitama Medical Center, Jichi Medical University, Saitama, Japan), which is a graphical user interface for $\mathrm{R}$ (The $\mathrm{R}$ Foundation for Statistical Computing, Vienna, Austria) [9]. More precisely, it is a modified version of $\mathrm{R}$ commander designed to add statistical functions frequently used in biostatistics.

\section{Results}

Two hundred of chronic HD male patients in 13 institutions participated in this study. Eight patients were excluded because they did not completed the EF domain from IIEF-5 in questionnaire, and 14 patients were also excluded because of their past history of medical treatment for ED. Thus, the sample was composed of 178 patients.

Patient's background was shown in Table 1. The number of patients whose duration of chronic HD was shorter than 10 years (group 1) was 128, and that of the others who received chronic HD more than 10 years (group 2) was 50. Mean duration of HD was $4.5 \pm 2.5$ years in group 1 and $17.3 \pm 5.4$ years in group $2(p<0.001)$. Body mass index (BMI) was significantly lower in group $2(p=0.011)$. The most frequent primary disease of end-stage renal disease was diabetes mellitus (DM) nephropathy in group 1 , while that in group 2 was chronic glomerular nephritis $(\mathrm{CGN})(p=0.016)$. The prevalence of DM was also higher in group $1(p<0.001)$. Group 1 had a high frequency of hyperuricemia $(p=0.010)$ and a lower frequency of liver dysfunction $(p=0.031)$. The prevalence of other comorbidities was not significantly different between the 2 groups. Chronic kidney disease mineral and bone disorder (CKD-MBD) status including serum calcium $(\mathrm{Ca})$, phosphate $(\mathrm{P})$, and intact parathyroid hormone (iPTH) levels was also compared between 104 of 128 patients and 41 of 50 patients whose data of these parameters could be collected from medical records. Serum Ca $(9.0 \pm 0.8 \mathrm{mg} / \mathrm{dL}$ and $9.1 \pm 0.8 \mathrm{mg} / \mathrm{dL} ; p=0.366), \mathrm{P}(5.7 \pm 1.7 \mathrm{mg} / \mathrm{dL}$ and $5.4 \pm 1.6 \mathrm{mg} / \mathrm{dL} ; p=0.477)$, and iPTH $(154.1 \pm 124.5 \mathrm{pg} / \mathrm{mL}$ and $147.3 \pm 125.7 \mathrm{pg} / \mathrm{mL} ; p=0.645$ ) were not significantly different between the 2 groups.

IIEF-5 scores and grade of ED assessed by IIEF-5 in each group were shown in Table 2. The mean score of IIEF-5 in group 2 was almost similar with that in group $1(p=0.452)$. The rate of each ED grade assessed by IIEF-5 score in group 2 was also comparable to that of group $1(p=0.959)$. Moderate to severe ED on the basis of IIEF-5 score in group 2 was $66 \%$, which was almost equivalent to $68 \%$ in group $1(p=0.849)$.

On univariate analysis, associated risk factors for moderate to severe ED on the basis of IIEF-5 score were age older than 60 years $(p<0.001)$ and absence of hyperuricemia $(p=0.008)$ (Table 3$)$. HD duration more than 10 years was demonstrated not to be the significant risk factor for moderate to severe $\operatorname{ED}(p=0.779)$. We also evaluated the relationship between ED and these risk factors in multivariate analysis. While HD duration also did not have significant correlation with moderate to severe ED in this analysis, age more than 60 years old $(p<0.001)$ and absence of hyperuricemia $(p=0.005)$ appeared to be important correlate of moderate to severe ED.

\section{Discussion}

As a result of improvement in HD therapy and small number of kidney transplantation due to extreme shortage of kidney donation in Japan, the number of both end-stage renal disease (ESRD) patients with long-term chronic HD therapy and patients who receive short period of chronic HD but have various comorbidities are gradually increasing [10]. Several cross-sectional studies revealed that ED is a very common disease in ESRD patients; however, the influence of long-term chronic HD for ED was not well evaluated. In this study, the frequency of ED was almost equivalent between short-term HD patients and long-term patients, and hyperuricemia was demonstrated to be an independent risk factor in not only all patients but also long-term hemodialysis patients. 
Table 1 Patient demographics

\begin{tabular}{|c|c|c|c|c|c|c|}
\hline & & & All patients & $\begin{array}{l}\text { Duration of } \mathrm{HD} \\
<10 \text { years patients }\end{array}$ & $\begin{array}{l}\text { Duration of } \mathrm{HD} \\
\geq 10 \text { years patients }\end{array}$ & $p$ values \\
\hline & & & & (Group $1 ; n=128)$ & & \\
\hline Age & mean $\pm S D$ & (years) & $59.2 \pm 10.7$ & $60.0 \pm 10.5$ & $57.4 \pm 11.0$ & 0.19 \\
\hline Duration of dialysis & mean $\pm S D$ & (years) & $8.1 \pm 6.8$ & $4.5 \pm 2.5$ & $17.3 \pm 5.4$ & $<0.001$ \\
\hline Body mass index & mean $\pm S D$ & $(\mathrm{~kg} / \mathrm{m} / \mathrm{m})$ & $23.5 \pm 8.4$ & $24.3 \pm 8.7$ & $21.2 \pm 7.1$ & 0.01 \\
\hline Primary renal diseases & & & & & & 0.02 \\
\hline Diabetes mellitus & $n$ & (\%) & $54(30)$ & $49(38)$ & $5(10)$ & \\
\hline Chronic glomerular nephritis & $n$ & (\%) & $64(36)$ & $34(27)$ & $30(60)$ & \\
\hline Hypertensive nephrosclerosis & $n$ & (\%) & $13(7)$ & $12(9)$ & $1(2)$ & \\
\hline Others & $n$ & (\%) & $47(26)$ & $33(26)$ & $14(28)$ & \\
\hline Comorbidities & & & & & & \\
\hline Hypertension & $n$ & (\%) & $156(88)$ & $115(90)$ & $41(82)$ & 0.19 \\
\hline Diabetes mellitus & $n$ & (\%) & $48(27)$ & $45(35)$ & $3(6)$ & $<0.001$ \\
\hline Hyperlipidemia & $n$ & (\%) & $25(14)$ & $20(16)$ & $5(10)$ & 0.47 \\
\hline Hyperuricemia & $n$ & (\%) & $42(25)$ & $37(29)$ & $5(10)$ & 0.010 \\
\hline Cardiovascular disease & $n$ & (\%) & $36(20)$ & $30(23)$ & $6(12)$ & 0.100 \\
\hline Cerebrovascular disease & $n$ & (\%) & $13(7)$ & $8(6)$ & $5(10)$ & 0.52 \\
\hline Liver dysfunction & $n$ & (\%) & $10(6)$ & $4(3)$ & $6(12)$ & 0.03 \\
\hline Depression & $n$ & (\%) & $2(1)$ & $2(2)$ & $0(0)$ & 1 \\
\hline Smoking & & & & & & 0.699 \\
\hline Former smoker & $n$ & (\%) & $90(51)$ & $62(48)$ & $28(56)$ & \\
\hline Current smoker & $n$ & (\%) & $41(23)$ & $31(24)$ & $10(20)$ & \\
\hline Alcohol consumption & & & & & & 0.39 \\
\hline Social drinker & $n$ & (\%) & 70 (39) & $47(37)$ & $23(46)$ & \\
\hline Daily drinker & $n$ & (\%) & $20(11)$ & $14(11)$ & $6(12)$ & \\
\hline Presence of sexual partner & $n$ & (\%) & $131(74)$ & 100 (78) & $31(62)$ & 0.08 \\
\hline
\end{tabular}

Various physiological changes including secondary hyperparathyroidism and arteriosclerosis due to prolonged chronic hemodialysis are well-known to be getting worsen progressively [11]. ED status in ESRD patients with long-term chronic HD was predicted to be progressed; however, long-term chronic HD did not appear to deteriorate ED status under adjustment of various factors. This is a cross-sectional study based on questionnaire and we could not include various clinical factors such as high-intact parathyroid hormone level, zinc deficiency, evaluation of malnutrition status, and degree of arteriosclerosis. Among these parameters, degree of arteriosclerosis might not be advanced in ESRD patients with long-term HD as strong as we suspected

Table 2 IIEF-5 score and ED status in HD patients

\begin{tabular}{|c|c|c|c|c|c|c|}
\hline & & & $\begin{array}{l}\text { All patients } \\
n=178\end{array}$ & $\begin{array}{l}\text { HD duration }<10 \text { years patients } \\
\text { (Group } 1 ; n=128 \text { ) }\end{array}$ & $\begin{array}{l}\text { HD duration } \geq 10 \text { years patients } \\
\text { (Group } 2 ; n=50 \text { ) }\end{array}$ & $p$ values \\
\hline IIEF-5 score & mean $\pm S D$ & & $8.9 \pm 7.1$ & $8.8 \pm 7.2$ & $9.2 \pm 6.8$ & 0.45 \\
\hline Grade of ED (IIEF-5 scores) & & & & & & 0.96 \\
\hline No ED (22-25) & $n$ & (\%) & $17(10)$ & $13(10)$ & $4(8)$ & \\
\hline Mild (17-21) & $n$ & (\%) & $16(9)$ & $11(9)$ & $5(10)$ & \\
\hline Mild to moderate (12-16) & $n$ & (\%) & $23(13)$ & $16(13)$ & $7(14)$ & \\
\hline Moderate (8-11) & $n$ & (\%) & $29(16)$ & $20(16)$ & $9(18)$ & \\
\hline Severe $(1-7)$ & $n$ & (\%) & $91(51)$ & $67(52)$ & $24(48)$ & \\
\hline
\end{tabular}


Table 3 Odds ratio of ED in HD patients for variables included in univariate analysis and multivariate analysis

\begin{tabular}{|c|c|c|c|c|c|c|}
\hline & \multicolumn{3}{|c|}{ Univariate analysis } & \multicolumn{3}{|c|}{ Multivariate analysis } \\
\hline & Odds ratio & $95 \% \mathrm{Cl}$ & $p$ value & Odds ratio & $95 \% \mathrm{Cl}$ & $p$ value \\
\hline Age $\geq 60$ years & 3.110 & $1.680-5.740$ & $<0.001$ & 3.610 & $1.890-6.880$ & $<0.001$ \\
\hline HD duration $\geq 10$ years & 0.910 & $0.473-1.750$ & 0.779 & & & \\
\hline $\mathrm{BMI} \geq 25$ & 0.736 & $0.394-1.38$ & 0.337 & & & \\
\hline Hypertension & 0.761 & $0.361-1.600$ & 0.472 & & & \\
\hline Diabetes mellitus & 1.830 & $0.928-3.600$ & 0.081 & & & \\
\hline Hyperlipidemia & 1.220 & $0.523-2.870$ & 0.642 & & & \\
\hline Hyperuricemia & 0.372 & $0.180-0.768$ & 0.008 & 0.303 & $0.139-0.656$ & 0.002 \\
\hline Cardiovascular disease & 1.400 & $0.668-2.930$ & 0.373 & & & \\
\hline Cerebrovascular disease & 1.540 & $0.484-4.910$ & 0.463 & & & \\
\hline Liver dysfunction & 0.606 & $0.165-2.230$ & 0.451 & & & \\
\hline Smoking & 0.803 & $0.563-1.140$ & 0.225 & & & \\
\hline Alcohol consumption & 0.714 & $0.460-1.110$ & 0.132 & & & \\
\hline Presence of sexual partner & 0.504 & $0.250-1.010$ & 0.055 & & & \\
\hline $\mathrm{Ca}>10 \mathrm{mg} / \mathrm{dL}$ & 0.437 & $0.125-1.520$ & 0.193 & & & \\
\hline$P>6 \mathrm{mg} / \mathrm{dL}$ & 0.969 & $0.475-1.980$ & 0.930 & & & \\
\hline iPTH > $250 \mathrm{pg} / \mathrm{mL}$ & 1.450 & $0.623-3.400$ & 0.387 & & & \\
\hline
\end{tabular}

$H D$ hemodialysis, $B M I$ body mass index, $E D$ erectile dysfunction, $C a$ calcium, $P$ phosphate, $I P T H$ intact parathyroid hormone

because the number of past history of CVD in patients with long-term HD was not larger than those in patient with short-term HD even though they had long duration of chronic kidney disease. Prospective cohort study which assess progression of ED status according to prolongation of hemodialysis period and include various clinical factors which are mentioned above might be more eligible to assess whether long-term HD affect ED severity or not.

Hyperuricemia was well-known as a risk factor for various vascular complications such as stroke, coronary disease, heart failure, and chronic kidney disease [12-15]. ED is closely associated with endothelial dysfunction and CVD, and the relationship between coronary artery disease and high uric acid level was reported [16]. On the other hand, inverse correlation between uric acid levels and all causes and CVD mortality in HD population was reported in contrast to the association of hyperuricemia and CVD risk in general population [17]. While the possibilities of surrogate for a better nutritional status and antioxidative properties of uric acid were pointed out, the potential mechanisms of this association in HD patients still remain uncertain $[17,18]$. This cardioprotective mechanism of hyperuricemia in HD population might contribute to lower frequency of ED.

There are various considerations in this study that limit our findings. First, this is a relatively small sample size cross-sectional study. Second, we enrolled only patients who accepted our proposal and filled out the questionnaire so that we could not reflect information on patients who refused to participate or excluded from the study cohort. Third, IIEF- 5 based on self-reporting was the only tool to evaluate ED in this study, and no other physical and diagnostic tests which evaluated not only ED status but also pathogenesis factors. Last, we could not assess influence of variables which have been reported to be linked to ED, such as autonomic neuropathy, residual renal function, hormonal status, anemia, secondary hyperparathyroidism, zinc deficiency, and so on. Prospective large cohort study including various clinical factors as mentioned above will be needed to address this subject.

\section{Conclusions}

In conclusion, longer periods of chronic HD therapy did not affect ED status, and there is reverse correlation between hyperuricemia and ED status of ESRD patients with either short or long periods of chronic HD. Further evaluation for the reason why hyperuricemia improve ED status in HD patients is needed.

\section{Abbreviations}

BMI: Body mass index; Ca: Calcium; CGN: Chronic glomerular nephritis; CKDMBD: Chronic kidney disease mineral and bone disorder; CVD: Cardiovascular diseases; DM: Diabetes mellitus; ED: Erectile dysfunction; ESRD: End-stage renal disease; HD: Hemodialysis; IIEF-5: International Index of Erectile Function-5; iPTH: Intact parathyroid hormone; OR: Odds ratio; P: Phosphate; SD: Standard deviation;

\section{Acknowledgements}

We acknowledge the support of the following investigators who participated in this study: Dr. Ikuto Masakane (Yabuki Hospital), Dr, Hideki Tanida (Yabuki Hospital), Dr. Minoru Ito (Yabuki Hospital), Dr. Katsuyuki Saito, Dr.Masashi 
Adachi (Yamagata Clinic), Dr. Takeshi Izumiya (Takahata Public Hospital), Dr. Ken Ataka (Tsuruoka City Shonai Hospital), Dr. Hiroshi Kakizaki (Nihonkai General Hospital), Dr. Takuya Yamanobe (Nihonkai General Hospital), Dr. Yoshiki Onmura (Okitama Public Nanyo Hospital), Dr. Kazutaka Sato (Yamagata Prefectural Shinjo Hospital), and Dr.Toshiyuki Takahashi (Yamagata Prefectural Central Hospital).

\section{Funding}

This study was sponsored by Nippon Shinyaku Co, LTD, Kyoto, Japan. The role of the funding body was a reward to the data collection of investigators in each chronic hemodialysis institution.

\section{Availability of data and materials}

Please contact author for data requests.

\section{Authors' contributions}

HN planned the study, searched the literature, assessed studies, extracted data, analyzed data, and prepared the article. AY, TS, SN, TS, HK, Ol, and TK assisted in the data analysis and article preparation. AN and YT planned the study and assisted in the data analysis and article preparation. NT assisted in the article preparation. All authors read and approved the final manuscript.

\section{Competing interests}

The authors declare that they have no competing interests.

\section{Consent for publication}

Not applicable.

\section{Ethics approval and consent to participate}

The study protocol was approved by the ethical committee of the Yamagata University Faculty of Medicine. Written informed consent was obtained from all subjects.

\section{Author details}

${ }^{1}$ Department of Urology, Yamagata University Faculty of Medicine, 2-2-2 lida-nishi, Yamagata 990-9585, Japan. '2Division of Urology, Department of Regenerative and Transplant Medicine, Graduate School of Medical and Dental Sciences, Niigata University, 757, Ichibancho, Asahimachidori, Chuo-ku, Niigata, Japan.

Received: 22 June 2016 Accepted: 2 November 2016

Published online: 22 December 2016

\section{References}

1. Rosas SE, Joffe M, Franklin E, Strom BL, Kotzker W, Brensinger C, et al. Prevalence and determinants of erectile dysfunction in hemodialysis patients. Kidney Int. 2001;59(6):2259-66.

2. Collaborative D, Sexual Dysfunction in Hemodialysis Working G, Vecchio M, Palmer S, De Berardis G, Craig J, et al. Prevalence and correlates of erectile dysfunction in men on chronic haemodialysis: a multinational crosssectional study. Nephrol Dial Transplant. 2012;27(6):2479-88.

3. Costa MR, Reis AM, Pereira BP, Ponciano VC, Oliveira EC. Associated factors and prevalence of erectile dysfunction in hemodialysis patients. Int Braz J Urol. 2014;40(1):44-55

4. Makarem AR, Karami MY, Zekavat OR. Erectile dysfunction among hemodialysis patients. Int Urol Nephrol. 2011;43(1):117-23.

5. El-Assmy A. Erectile dysfunction in hemodialysis: a systematic review. World J Nephrol. 2012;1(6):160-5.

6. Suzuki E, Nishimatsu H, Oba S, Takahashi M, Homma Y. Chronic kidney disease and erectile dysfunction. World J Nephrol. 2014;3(4):220-9.

7. Shen YC, Weng SF, Wang JJ, Tien KJ. Erectile dysfunction and risk of end stage renal disease requiring dialysis: a nationwide population-based study. PLOS One. 2014:9(7):e102055

8. Stolic RV, Bukumiric ZM, Jovanovic AN, Peric VM, Sovtic SR, Belic BP, et al. Residual renal function and erectile dysfunction in patients on hemodialysis. Int Urol Nephrol. 2012;44(3):891-5.

9. Kanda Y. Investigation of the freely available easy-to-use software 'EZR' for medical statistics. Bone Marrow Transplant. 2013:48(3):452-8.

10. Nakai S, Watanabe Y, Masakane I, Wada A, Shoji T, Hasegawa T, et al. Overview of regular dialysis treatment in Japan (as of 31 December 2011). Ther Apher Dial. 2013;17(6):567-611.
11. Piccoli GB, Mezza E, Anania P, ladarola AM, Vischi M, Torazza MC, et al Patients on renal replacement therapy for 20 or more years: a clinical profile. Nephrol Dial Transplant. 2002;17(8):1440-9.

12. Li M, Hou W, Zhang $X, H u$ L, Tang Z. Hyperuricemia and risk of stroke: a systematic review and meta-analysis of prospective studies. Atherosclerosis. 2014;232(2):265-70

13. Bickel C, Rupprecht HJ, Blankenberg S, Rippin G, Hafner G, Daunhauer A, et al. Serum uric acid as an independent predictor of mortality in patients with angiographically proven coronary artery disease. Am J Cardiol. 2002; 89(1):12-7.

14. Huang $H$, Huang B, Li Y, Huang Y, Li J, Yao H, et al. Uric acid and risk of heart failure: a systematic review and meta-analysis. Eur J Heart Fail. 2014; 16(1):15-24.

15. Sedaghat S, Hoorn EJ, van Rooij FJ, Hofman A, Franco OH, Witteman JC, et al. Serum uric acid and chronic kidney disease: the role of hypertension. PLoS One. 2013;8(11):e76827.

16. Solak Y, Akilli H, Kayrak M, Aribas A, Gaipov A, Turk S, et al. Uric acid level and erectile dysfunction in patients with coronary artery disease. J Sex Med. 2014;11(1):165-72

17. Latif W, Karaboyas A, Tong L, Winchester JF, Arrington CJ, Pisoni RL, et al. Uric acid levels and all-cause and cardiovascular mortality in the hemodialysis population. Clin J Am Soc Nephrol. 2011:6(10):2470-7.

18. Suzuki T. Nitrosation of uric acid induced by nitric oxide under aerobic conditions. Nitric Oxide. 2007;16(2):266-73.

\section{Submit your next manuscript to BioMed Central and we will help you at every step:}

- We accept pre-submission inquiries

- Our selector tool helps you to find the most relevant journal

- We provide round the clock customer support

- Convenient online submission

- Thorough peer review

- Inclusion in PubMed and all major indexing services

- Maximum visibility for your research

Submit your manuscript at www.biomedcentral.com/submit
) Biomed Central 